\title{
Intact retrieval inhibition in children's episodic recall
}

\author{
MARTINA ZELLNER and KARL-HEINZ BÄUML \\ Regensburg University, Regensburg, Germany
}

\begin{abstract}
Young children are assumed to be inefficient inhibitors in a number of cognitive tasks. In two experiments, we examined whether such deficits extend to children's episodic recall. We used two inhibition paradigms: retrieval-induced forgetting, the detrimental effect of retrieval practice with a subset of learned items on recall of the unpracticed items, and part-list cuing, the detrimental effect of the presentation of a subset of learned items on recall of the remaining items. In both experiments, the inhibitory effects were compared across three age groups: first or second graders, fourth graders, and young adults. The two children groups showed the same amounts of retrieval-induced forgetting and part-list cuing as the adult group, pointing to intact retrieval inhibition in young children's episodic recall. These results parallel very recent results on older adults' episodic recall, suggesting that both retrieval-induced forgetting and part-list cuing develop early in life and remain intact for the greater part of the lifespan.
\end{abstract}

Teachers sometimes complain about young children's failures to focus their attention, overcome impulsive motor responses, or withhold their answers up to the appropriate moment. These behaviors are often attributed to a general lack of inhibitory control. That is, children cannot suppress a prepotent reaction in favor of a more adequate one. Experimental work has shown children's inhibition deficits in many different tasks, such as object permanence (Diamond, 1988), verbal self-regulation (Luria, 1961), selective attention (e.g., Tipper, Bourque, S. H. Anderson, \& Brehaut, 1989), speeded classification (e.g., Strutt, D. R. Anderson, \& Well, 1975), and lexical ambiguity processing (e.g., Simpson \& Foster, 1986). Accordingly, developmental improvements are often proposed to derive from increasingly efficient inhibition mechanisms. By inhibiting inadequate responses or irrelevant information, children are more and more able to control motor responses, allocation of attention, and complex cognitive mechanisms in an efficient way, thereby improving task performance.

Bjorklund and Harnishfeger (1990) have proposed that inhibition plays a substantial role in memory development as well. They suggested that, initially, children do not possess the capability to suppress the activation of taskirrelevant information, during both encoding and mem-

Part of the research reported in this article was presented at the 13th Meeting of the European Society for Cognitive Psychology (ESCoP, September 2003, Granada, Spain). It was supported by Grant FOR 448 from the Deutsche Forschungsgemeinschaft to K.-H.B. We thank M. Reysen, H. L. Roediger III, and M. C. Anderson for their comments on a previous version of the article. Correspondence should be addressed to K.-H. Bäuml, Department of Experimental Psychology, Regensburg University, 93040 Regensburg, Germany (e-mail: karlheinz.baeuml@psychologie.uni-regensburg.de). ory retrieval. The irrelevant material occupies processing capacity and storage space that otherwise would be available for the memory task (Harnishfeger \& Bjorklund, 1993). By learning to inhibit irrelevant and distracting material, children's resource management becomes more effective, and as a result, memory performance improves.

An important line of evidence for the inefficient inhibition hypothesis is the inability of young children to intentionally forget material from episodic memory when cued to do so. In the list method of directed forgetting, subjects study two lists of items. After the presentation of List 1, they receive a cue to either forget or continue remembering this list while studying List 2. As compared with remember-cued subjects, forget-cued subjects typically show impaired recall of List 1 and improved recall of List 2 items (R. A. Bjork, 1970, 1989). This pattern of results has often been explained in terms of inhibition. The assumption is that, by inhibiting List 1 items, the forget cue reduces interference from List 1 and, thus, facilitates retrieval of List 2 items (see MacLeod, 1998, for a review). Young children, such as first and third graders, fail to show directed forgetting and show hardly any effect of the forget cue at all. Normal directed-forgetting performance, however, is present from the fifth grade on (Bray, Justice, \& Zahm, 1983; Harnishfeger \& Pope, 1996). The inhibition mechanism apparently develops over the elementary school years. ${ }^{1}$

In episodic memory, inhibition has been proposed not only to underlie directed forgetting, but to mediate retrieval-induced forgetting as well. In retrieval-induced forgetting, subjects repeatedly retrieve a subset of previously learned material. The retrieval practice typically facilitates subsequent recall of the practiced items but impairs recall of the unpracticed material, as compared with a control condition in which there is no retrieval practice at all 
(M. C. Anderson, R. A. Bjork, \& E. L. Bjork, 1994; M. C. Anderson \& Spellman, 1995; Bäuml, 2002; Ciranni \& Shimamura, 1999). This pattern of results has been assumed to reflect inhibition. The not-to-be-practiced items interfere during retrieval practice, and to guarantee a successful recovery of to-be-practiced items, the interference is reduced, and the not-to-be-practiced items are suppressed (see M. C. Anderson, 2003, or Levy \& M. C. Anderson, 2002, for reviews). To our knowledge, no developmental studies have yet been conducted in which the emergence of this inhibition mechanism has been investigated.

Following the inefficient inhibition hypothesis, it might be tempting to argue that young children have poor retrieval inhibition in general and that they should show not only poor directed forgetting, but poor retrievalinduced forgetting as well. In fact, because the two forms of inhibition appear to share a similar goal-facilitating the retrieval of relevant material by avoiding the interference of irrelevant material - and show other parallels as well (E. L. Bjork, R. A. Bjork, \& M. C. Anderson, 1998; Conway, Harries, Noyes, Racsma'ny, \& Frankish, 2000), they might become efficient at around the same age. Then, young children, such as first and third graders, should have problems in suppressing the interfering material during retrieval practice and, as a result, retrieval-induced forgetting, like directed forgetting, should be reduced.

There are at least two reasons, however, why such a prediction might be premature. First, directed forgetting occurs with intentional effort and is dependent on conscious control. It has been found to require a high amount of attentional capacity and to be reduced, or even eliminated, if a secondary task is introduced (Conway et al., 2000; Macrae, Bodenhausen, Milne, \& Ford, 1997). This pattern suggests that directed forgetting depends to a large extent on controlled processes. Consistently, older adults, who have been argued to show a deficit in cognitive control (e.g., N. D. Anderson \& Craik, 2000), have been found to show reduced directed forgetting (Zacks, Radvansky, \& Hasher, 1996). By contrast, older adults appear to show robust retrieval-induced forgetting (Moulin et al., 2002), suggesting that directed forgetting and retrieval-induced forgetting differ in cognitive control, with a higher amount of control involved in directed forgetting than in retrievalinduced forgetting.

There is evidence that young children, like older adults, have problems in memory tasks that rely on controlled processes. Bjorklund and Zeman (1982), for instance, observed children from the first and fifth grades as they tried to recall the names of their current classmates. In contrast to the fifth graders, the first graders showed poor clustering and were hardly aware of how they managed to retrieve the names. Similarly, Kobasigawa (1974) and Ackerman (1996) showed that young children fail to use retrieval cues and retrieval strategies. In fact, memory processes involving a higher amount of controlled processes appear to develop later than those involving a lower amount (Haberlandt, 1999). If this pattern generalizes to the development of inhibitory pro- cesses, retrieval-induced forgetting might well be present in young children, thus contrasting with the finding of young children's impaired directed forgetting.

A second reason why the directed-forgetting findings might not generalize to retrieval-induced forgetting has to do with recent studies in which the inhibition account of directed forgetting has been challenged. Sahakyan and Kelley (2002), for instance, have provided evidence that the benefits and costs of directed forgetting result from an internal context change that occurs between the presentation of the two lists in response to the forget instruction, rather than from inhibition. In accord with this proposal, Sahakyan and Kelley found effects similar to directed forgetting when they simply induced a mental context change in a group instructed to remember both lists of words. MacLeod, Dodd, Sheard, Wilson, and Bibi (2003) also have questioned the inhibition account of directed forgetting. In a series of experiments, they provided evidence that the benefits and costs of directed forgetting result from selective rehearsal of List 1 across the forget and remember groups. On the basis of these findings, they favored a rehearsal explanation of directed forgetting over the more traditional inhibition account.

If the suggestions by Sahakyan and Kelley (2002) and MacLeod et al. (2003) are right and directed forgetting is not the result of retrieval inhibition, young children's reduced directed forgetting found in prior work (Bray et al., 1983; Harnishfeger \& Pope, 1996) would point to children's inefficiency in changing a mental context, or their inefficiency in rehearsal processes, rather than to poor retrieval inhibition. In such a case, no evidence for inefficient retrieval inhibition in children's episodic recall would exist to date. The question would arise as to whether inefficient inhibition in children, which has been demonstrated in a number of cognitive tasks (see above), extends to episodic memory and, in particular, retrieval-induced forgetting. We addressed the issue in two experiments.

\section{EXPERIMENT 1}

Using M. C. Anderson et al.'s (1994) retrieval practice paradigm, in Experiment 1 we studied the detrimental effects of retrieval practice across three age groups: second graders, fourth graders, and young adults. All three subject groups learned lists of items that they were asked to recall at a later point in time. There was a practice and a no-practice condition, which differed only in the retention phase of the experiment. In the practice condition, the subjects repeatedly retrieved half of the studied items, given the word stems of the items as retrieval cues; in the no-practice condition, no items were practiced, and a distractor task was carried out instead. For all three subject groups, we examined whether the retrieval practice on some of the learned items impaired later recall of the unpracticed items. In addition, we examined whether the amount of recall impairment was different for the three subject groups. 


\section{Method}

Subjects. Twenty-four second graders (age, $M=7.4$ years, $S D=$ 0.49 years; 18 males and 6 females) and 24 fourth graders (age, $M=9.4$ years, $S D=0.50$ years; 12 males and 12 females) participated in the experiment. They were recruited from a primary school near Regensburg, Germany, and participated on a voluntary basis. In addition, 24 psychology students at the University of Regensburg (age, $M=23.2$ years, $S D=2.6$ years; 5 males and 19 females) participated as an adult control group.

Materials. Items were selected from German association norms for children in the second grade, children in the fourth grade, and adults (Hasselhorn \& Grube, 1994). The items were chosen from four different semantic categories: animals, tools, clothes, and furniture. From each of the four categories, 2 cue items were selected (e.g., horse and owl from the animals category, or vise and rake from the tools category), and for each cue item, an item list was constructed by choosing 8 (children) or 10 (adults) strong associates to the particular cue. In this way, for each subject group, eight lists each consisting of 8 (children) or 10 (adults) items were created. ${ }^{2}$

Design. Each subject participated in two experimental conditions: the practice condition and the no-practice condition. Half of the subjects within a group started with the practice condition, the other half with the no-practice condition. Two lists, which were from different categories (e.g., the horse and the rake lists), were presented to each subject, one list in the practice and the other in the no-practice condition. The single categories were used equally often in the two conditions. A category's first list was used for one half of the subjects, the category's second list for the other half.

Procedure. In both the practice and the no-practice conditions, the subjects were presented a list that later they were asked to recall. The two conditions differed in the retention phase only. In the practice condition, the subjects repeatedly retrieved half of the presented list and then worked through the distractor task. Retrieval practice was on the four (children) or five (adults) list items with the relatively weakest association to the common item cue. In the nopractice condition, no items were practiced, and instead, an extended distractor task was carried out. After the distractor task, in both conditions, all of a list's items had to be recalled. In the practice condition, the subjects were explicitly told to recall both a list's practiced and its unpracticed items.
For list presentation, an audio tape was played on which a female voice spoke the items at a rate of one word every $2 \mathrm{sec}$. The order of the words was held constant. Depending on list category, the children were told a little story about the content of the list. For example, for the tools category, the instruction said the following. "Yesterday, Suzanne helped her grandfather to do some workings at home. Thereafter, Suzanne recorded onto this tape here what she had seen at her grandfather's house. You can now listen to the tape. Try to remember everything that Suzanne mentioned." Then the audio tape was played. No cover story was told for the adults.

In the practice condition, the subjects were cued auditorily by the (unique) word stem of a particular item and had to answer with the correct item. Word stems consisted of the first two or three letters of the word, depending on word length. The items were practiced in two consecutive blocks, with no break between the blocks. The order of the items within a block was random. Each item had to be retrieved once within each block. Retrieval practice was followed by a 2-min trail-making distractor task for the children and a 5-min math problem solving task for the adults. In the no-practice condition, the two distractor tasks were extended in time to match the duration of the retrieval practice phase.

After the distractor task, in both conditions, recall was assessed. The subjects were asked to recall as many of the words from the tape as possible. They had 1 min for this task. Recall was written down by the experimenter. There was a break of 2 min between the two experimental conditions.

As has been outlined, there were three small procedural differences between the two children groups and the adult group: The adults received 10 rather than 8 items per list, they received no cover story for the presentation of the items, and the distractor task was more demanding and prolonged. These differences were introduced to adjust task difficulty across subject groups. There were no further differences.

\section{Results}

The repeated retrieval of items in the practice phase was successful. Overall, $96 \%$ of the word stems were correctly completed. Success rates in Grade 2, Grade 4, and the adult group averaged $94.8 \%, 95.8 \%$, and $97.5 \%$,

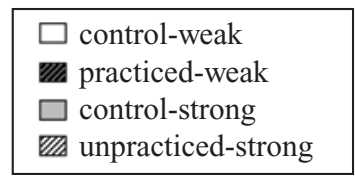

2nd graders

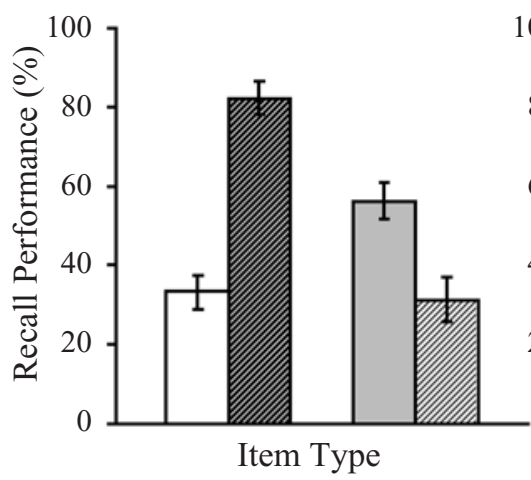

4th graders

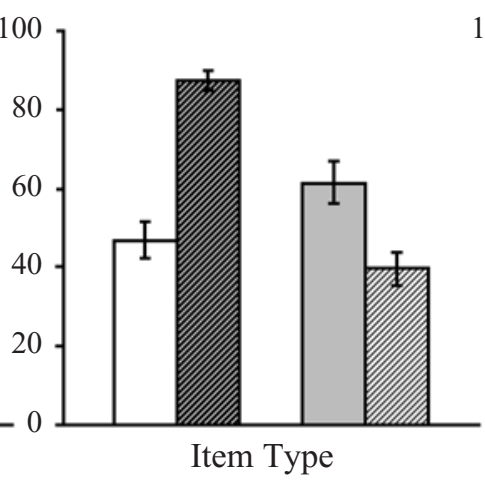

adults

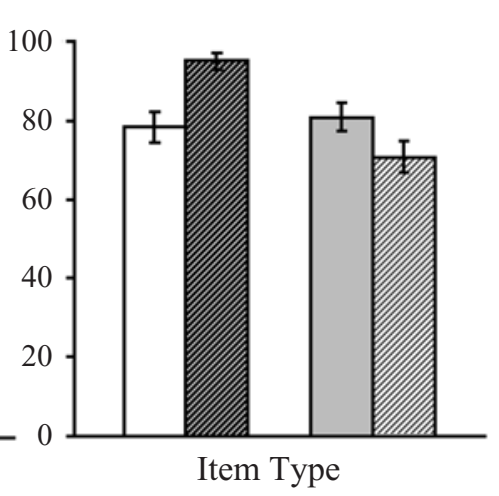

Figure 1. Retrieval-induced forgetting (Experiment 1): recall of practiced, unpracticed, and control items in second graders, fourth graders, and adults. 
respectively. The slight differences across subject groups were not reliable $[F(2,69)<1]$.

Figure 1 illustrates the recall levels for the three types of items for all three subject groups. Note that there were two types of control items; a category's relatively weak items, which served as a control for the practiced items, and a category's relatively strong items, which served as a control for the unpracticed items. The figure suggests that all three subject groups showed impaired recall of unpracticed items, as compared with recall of the control items, and showed about the same amount of impairment. This suggestion was supported by a $2 \times 3$ analysis of variance (ANOVA) with the two factors of item type (unpracticed or control) and subject group (adults, fourth graders, or second graders). The analysis yielded significant main effects of item type $[F(1,69)=27.0$, $\left.M S_{\mathrm{e}}=0.048, p<.001\right]$ and subject group $[F(2,69)=$ $\left.24.6, M S_{\mathrm{e}}=0.056, p<.001\right]$ but no significant interaction between the two factors $\left[F(2,69)=1.6, M S_{\mathrm{e}}=\right.$ $0.048, p=.22]$.

Figure 1 additionally suggests that all three subject groups showed recall enhancement for the practiced items, as compared with recall of the control items. This enhancement was about the same for the two children groups but, due to a ceiling effect for the adults, somewhat higher for the two children groups than for the adult group. Again, the suggestion was supported by a $2 \times 3$ ANOVA with the two factors of item type (practiced or control) and subject group (adults, fourth graders, or second graders). The analysis yielded significant main effects of item type $\left[F(1,69)=121.5, M S_{\mathrm{e}}=0.037, p<\right.$ $.001]$ and subject group $\left[F(2,69)=31.9, M S_{\mathrm{e}}=0.033\right.$, $p<.001]$ and a significant interaction between the two factors $\left[F(2,69)=9.1, M S_{\mathrm{e}}=0.037, p<.001\right]$. This interaction, however, was no longer present when only the two children groups were analyzed $[F(1,46)<1]$.

\section{Discussion}

Previous studies have shown that retrieval practice on a subset of previously learned items facilitates subsequent recall of the practiced material and inhibits subsequent recall of the unpracticed material (M. C. Anderson et al., 1994; M. C. Anderson \& Spellman, 1995). Our results extend this prior work with adults by demonstrating that young children also show retrieval inhibition in this type of task. In fact, not only adults, but also fourth graders and second graders revealed a facilitating effect of retrieval practice on recall of the practiced material and an inhibiting effect on recall of the unpracticed material. In particular, the amount of inhibition was largely the same in the three age groups.

Our results for children's retrieval-induced forgetting differ from those found in previous studies of directed forgetting, in which normal directed forgetting was found in fifth graders but no forgetting arose in first and third graders (Bray et al., 1983; Harnishfeger \& Pope, 1996). With respect to the inhibition account of directed forget- ting (R. A. Bjork, 1989), this difference between the two forms of forgetting indicates that there is no general deficit in young children's retrieval inhibition. Rather, whether or not young children can inhibit interfering material is task dependent. With respect to the more recent noninhibitory accounts of directed forgetting (MacLeod et al., 2003; Sahakyan \& Kelley, 2002), the results suggest that the inhibitory deficits found with a number of cognitive tasks may not extend to episodic recall.

\section{EXPERIMENT 2}

Experiment 1 provided a first indication for intact retrieval inhibition in children's episodic recall. Our goal in Experiment 2 was to verify the generalizability of this finding and, in addition, to include a second inhibition paradigm besides the retrieval practice paradigm. We chose part-list cuing. Part-list cuing refers to the detrimental effect of the presentation of a subset of previously learned items as retrieval cues on recall of the remaining noncue items. Since Slamecka's (1968) first demonstration, there has been a large number of studies in which such a detrimental effect has been reported (see Nickerson, 1984, or Roediger \& Neely, 1982, for reviews). The effect has been found to be fairly robust, occurring with both categorized and uncategorized lists and with either intralist or extralist items as cues.

It has recently been argued that not only retrievalinduced forgetting, but also part-list cuing is caused by retrieval inhibition (M. C. Anderson et al., 1994; Bäuml \& Aslan, 2004; Bäuml \& Kuhbandner, 2003). Whereas in retrieval-induced forgetting the overt retrieval of practiced items is supposed to cause the inhibition of unpracticed items (M. C. Anderson et al., 1994; M. C. Anderson \& Spellman, 1995), in part-list cuing the covert retrieval of cue items has been suggested to cause the inhibition of noncue items. During attempts to recall the noncue items, such covert retrieval can cause retrievalinduced inhibition of noncue items and, thus, lead to the detrimental effect of part-list cuing (for an alternative, noninhibitory account of part-list cuing, see Basden \& Basden, 1995, and the General Discussion section).

In accord with the inhibitory account of part-list cuing, the results from several recent studies have indicated that the detrimental effects of retrieval practice and part-list cuing share a number of parallels. For instance, in both retrieval-induced forgetting (M. C. Anderson et al., 1994) and part-list cuing (Bäuml, Kissler, \& Rak, 2002), forgetting occurs for categories' high-frequency, but not for categories' low-frequency, items. Not only the presentation of semantically related extralist items as retrieval cues (Roediger, Stellon, \& Tulving, 1977) but also the generation of such extralist items (Bäuml, 2002) can cause forgetting of previously learned material. Finally, providing a direct comparison of the effects of retrieval practice and part-list cuing with Deese-RoedigerMcDermott lists (Roediger \& McDermott, 1995), Bäuml 
and Kuhbandner (2003) reported that retrieval practice and part-list cuing reduce both "critical" items' veridical recall and their false recall.

Following the inhibition account of part-list cuing, we examined both children's retrieval-induced forgetting and their part-list cuing. We studied the two forms of episodic forgetting across three age groups: first graders, fourth graders, and young adults. All three subject groups were presented lists of items and recalled the lists under three testing conditions: (1) a free recall condition, which served as the control condition, (2) a part-list cuing condition, in which half of the studied items were provided as retrieval cues at test for recall of the remaining items, and (3) a (modified) retrieval practice condition, in which half of the studied items were retrieved in the first step before, in the second step, the remaining items had to be recalled.

Previous studies showed that the retrieval of a first set of items during test typically impairs subsequent recall of a second set (Bäuml, 1998; Roediger \& Schmidt, 1980; Smith, 1971) and that the detrimental effect in this modified variant of the retrieval practice paradigm is of about the same size as the detrimental effect in the standard variant (Bäuml \& Hartinger, 2002). ${ }^{3}$ In this experiment, we chose the modified variant of the retrieval practice paradigm to allow as direct a comparison as possible of the detrimental effects of retrieval practice and part-list cuing (see Bäuml \& Aslan, 2004, for a discussion of this point). Such a direct comparison in both children's and adults' episodic recall can cast further light on the question of to what extent retrieval-induced forgetting and part-list cuing are mediated by the same mechanism.

On the basis of the results of Experiment 1, we expected to find retrieval-induced forgetting for both children groups in Experiment 2 as well. On the basis of the retrieval inhibition account of part-list cuing, we expected to find the same results in part-list cuing. The results concerning part-list cuing arrive at a time when no developmental studies have yet been reported in which the effect of part-list cuing in young children was studied.

\section{Method}

Subjects. Twenty-four first graders (age, $M=7.0$ years, $S D=$ 0.28 years; 14 males and 10 females) and 24 fourth graders (age, $M=10.2$ years, $S D=0.50$ years; 11 males and 13 females) participated in the experiment. They were recruited from a primary school in Regensburg, Germany, and participated on a voluntary basis. In addition, 24 adults (age, $M=21.0$ years, $S D=0.69$ years; 11 males and 13 females) participated as a control group.

Materials. For each subject group, four of the eight lists employed in Experiment 1 were also used in Experiment 2. From each of Experiment 1's four categories, one list was selected to result in four lists with 8 (children) or 10 (adults) items each.

Design. There were three experimental conditions: the retrieval practice condition, the part-list cuing condition, and the control condition. Each subject participated in all three conditions. The order of conditions was counterbalanced across subjects. Each of the four lists employed in the experiment was used equally often in the three conditions.
In each condition, the subjects studied a list and subsequently worked through a distractor task. The three conditions differed in testing conditions only. In the retrieval practice condition, there was a two-stage recall test with a word stem completion task for half of the studied items (nontarget items) in the first stage and an immediately following recall test for the remaining items (target items) in the second. In the part-list cuing condition, half of the studied items (nontarget items) were presented intact to subjects for use as a retrieval cue, and the subjects were asked to use these items for recall of the remaining items (target items). In the control condition, there was a free recall of all of the studied items, including both the target and the nontarget items.

Procedure. Overall, the procedure was similar to that in Experiment 1 . At the outset, the children were told a little story about the to-be-presented items. Then, to both the children and the adults, a list was presented from an audio tape at a rate of one word every $2 \mathrm{sec}$. The order of the words was held constant. Item presentation was followed by a 2-min trail-making distractor task for the children and a 5-min math problem solving task for the adults. Subsequently, the recall test was given.

The retrieval practice condition was largely identical to that in Experiment 1, with the main exception that the practice phase was shifted to the test phase. So, the subjects first had to complete the auditorily presented word stems of the list's four (children) or five (adults) weakest associations to the list's cue item (nontarget items), before they were asked to recall the list's remaining items (target items). In the part-list cuing condition, the subjects were told that they would hear some of the studied items, to help them recall the remaining items. Then the list's four (children) or five (adults) weakest associations to the common cue item (nontarget items) were read in random order at a rate of one item every $2 \mathrm{sec}$, and the subjects were asked to recall the remaining items (target items). Detrimental effects of part-list cuing have been demonstrated both when cues were presented at test and when cues were presented before test (Bäuml \& Aslan, 2004; Roediger et al., 1977). Although the detrimental effect of cuing is slightly reduced in the beforevariant (Roediger et al., 1977), this variant facilitates the direct comparison of the detrimental effects of retrieval practice and partlist cuing. The control condition was identical to that in Experiment 1 . The subjects were merely asked to recall as many of the words from the tape as they could.

In each of the three conditions, there was $1 \mathrm{~min}$ for item recall, which was written down by the experimenter. There was a break of 2 min between experimental conditions. The differences between the children and the adult groups in procedure were identical to those in Experiment 1. There were no further differences.

\section{Results}

Recall rates for the nontarget items in the retrieval practice phase were $76.0 \%$ in Grade 1, 82.3\% in Grade 4, and $87.5 \%$ in the adult group. Although success rates thus increased with the subjects' age, this tendency was not reliable $\left[F(2,69)=2.1, M S_{\mathrm{e}}=0.037, p=.13\right]$.

For all three subject groups, Figure 2 illustrates the effect of retrieval practice and part-list cuing with the nontarget items on recall of the target items. The figure suggests that, for all three subject groups, retrieval practice impaired target item recall, as compared with the control condition, and induced about the same amount of impairment for each of the subject groups. A $2 \times 3$ ANOVA with the two factors of item type (unpracticed or control) and subject group (adults, fourth graders, or first graders) confirmed this suggestion. The analysis yielded significant main effects of item type $[F(1,69)=19.9$, 


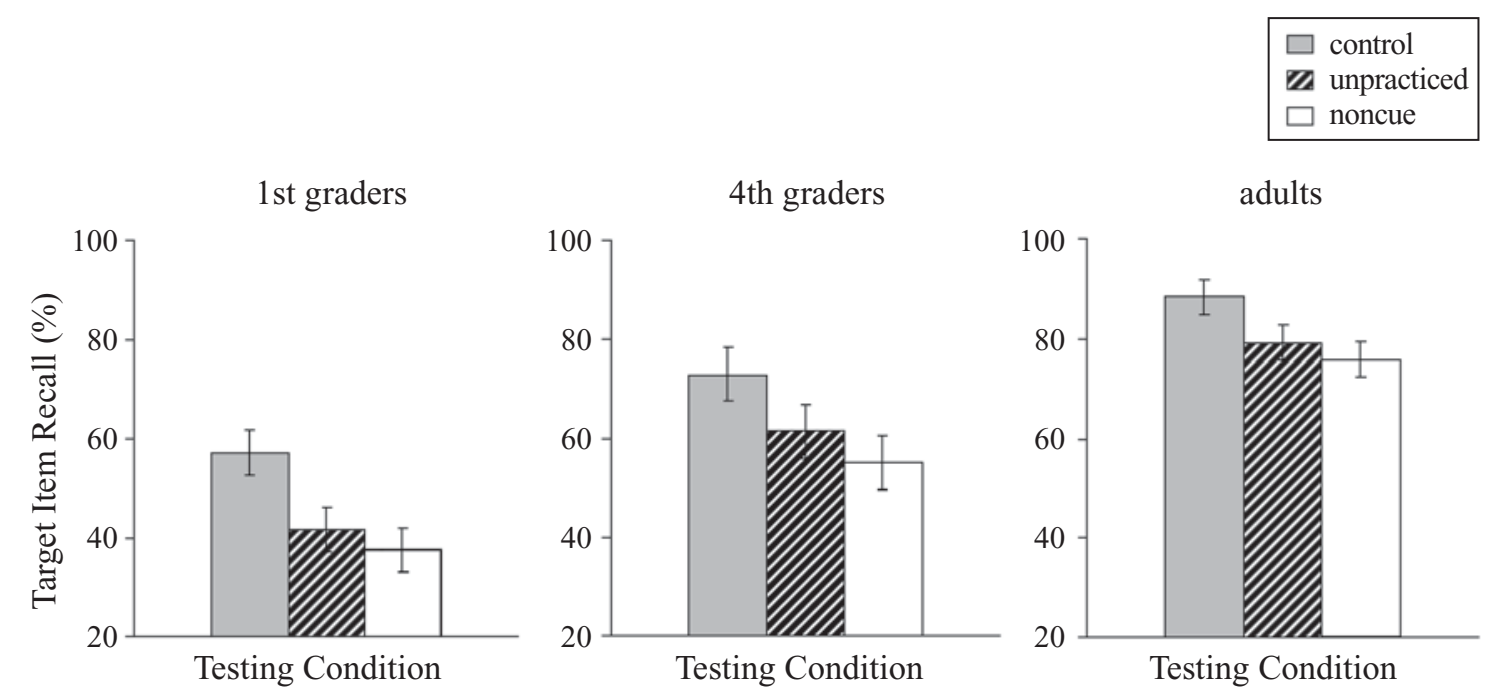

Figure 2. Retrieval-induced forgetting and part-list cuing (Experiment 2): recall of control, unpracticed, and noncue items in first graders, fourth graders, and adults.

$\left.M S_{\mathrm{e}}=0.026, p<.001\right]$ and subject group $[F(2,69)=34.2$, $\left.M S_{\mathrm{e}}=0.050, p<.001\right]$ but no significant interaction between the two factors $[F(2,69)<1]$, thus replicating the results in Experiment 1.

Figure 2 also suggests that, for all three subject groups, part-list cuing impaired target item recall and induced about the same detrimental effect in each of the subject groups. Indeed, a $2 \times 3$ ANOVA with the two factors of item type (noncue or control) and subject group (adults, fourth graders, or first graders) yielded significant main effects of item type $[F(1,69)=20.2$, $\left.M S_{\mathrm{e}}=0.049, p<.001\right]$ and subject group $[F(2,69)=$ $\left.25.3, M S_{\mathrm{e}}=0.057, p<.001\right]$ but no significant interaction between the two factors $[F(2,69)<1]$.

To examine whether retrieval practice and part-list cuing differed in their detrimental effects, a $2 \times 3$ ANOVA with the two factors of item type (unpracticed or noncue) and subject group (adults, fourth graders, or first graders) was performed. The analysis revealed a main effect of subject group $\left[F(2,69)=26.2, M S_{\mathrm{e}}=0.054, p<\right.$ $.001]$, but there was no main effect of item type $\left[F(1,69)=1.9, M S_{\mathrm{e}}=0.039, p=.17\right]$ and no significant interaction between the two factors $[F(2,69)<1]$. Retrieval practice and part-list cuing thus induced about the same detrimental effects on recall of the target items.

Further analyses and data. The results of both Experiments 1 and 2 showed significantly higher recall rates for the adult group than for the two children groups. This difference in recall rates might have implications for the processes that mediate inhibition and, thus, might have affected our results. To come up with a first rough test of whether recall level might have affected our results, we split our adult subject group into good rememberers and poor rememberers, according to whether their recall performance in the control condition was above or below mean recall. Although the good rememberers re- called more items than the poor rememberers did $(96.4 \%$ vs. $81.5 \%$ ), the amount of retrieval-induced forgetting and part-list cuing did not vary significantly with subject group $\left[F_{\mathrm{s}}(1,22)<1\right]$, as was indicated by two separate $2 \times 2$ ANOVAs with the two factors of subject group (good or poor rememberers) and item type (noncue/ unpracticed or control). ${ }^{4}$

We also repeated Experiment 2 for another 24 adult subjects. To reduce the adults' recall rates, we increased list length from 10 to 20 items by adding a 2 nd cue item from the same category to each list (see the Method section in Experiment 1). For each of the two cues, the 5 relatively weak items served as the nontarget items and were retrieval practiced or presented as retrieval cues at test. The 5 relatively strong items from each category served as the target items. Although the increase in list length reduced recall rates substantially - and made them comparable to those for the two children groupsthe same pattern arose as that reported above for the 10item lists.

Mean recall of target items was $68.3 \%$ in the control condition, $56.2 \%$ in the retrieval practice condition, and $57.9 \%$ in the part-list cuing condition. A $2 \times 3$ ANOVA with the two factors of list length (10 or 20 items) and testing condition (unpracticed, noncue, or control) revealed significant main effects of list length $[F(1,46)=$ $\left.29.4, M S_{\mathrm{e}}=0.050, p<.001\right]$ and testing condition $\left[F(2,92)=8.2, M S_{\mathrm{e}}=0.024, p<.001\right]$ but no significant interaction between the two factors $[F(2,92)<1]$. Thus, level of recall did not influence the detrimental effects of retrieval practice and part-list cuing in the present experiment.

\section{Discussion}

The result of retrieval-induced forgetting in young children replicates the main finding in Experiment 1. 
First graders were already found to show an inhibitory effect of retrieval practice on recall of the unpracticed material, and the size of this inhibitory effect was roughly the same as that in older children and adults. This finding confirms the suggestion that, with regard to retrieval-induced forgetting, young children show intact retrieval inhibition in their episodic recall.

Part-list cuing induced detrimental effects on recall of the noncue items as well. Again, this recall impairment occurred not only in adults, but also in the two children groups. The size of the effect was roughly the same in the three subject groups. Thus, also with regard to part-list cuing, children showed intact retrieval inhibition in their episodic recall. In agreement with the results from very recent work (Bäuml \& Aslan, 2004; Bäuml \& Kuhbandner, 2003), the detrimental effect of part-list cuing did not differ from that of retrieval practice, either in pattern or in size.

\section{GENERAL DISCUSSION}

With a directed-forgetting paradigm, previous studies have reported inhibitory deficits in children's episodic recall. In these studies, it was found that first and third graders failed to forget a previously learned list when cued to do so, whereas from fifth grade on, directed forgetting was present (Bray et al., 1983; Harnishfeger \& Pope, 1996). On the basis of the inhibition account of directed forgetting (R. A. Bjork, 1989), this failure has been interpreted as evidence for impaired inhibition in children's episodic recall (but see MacLeod et al., 2003, and Sahakyan \& Kelley, 2002, for alternative, noninhibitory accounts). Using the retrieval practice paradigm and the part-list cuing paradigm, both of which have been attributed to inhibition as well (M. C. Anderson et al., 1994; Bäuml \& Aslan, 2004), in the present article, we have examined whether the results from the directedforgetting paradigm generalize to other inhibition paradigms. No evidence for an inhibitory deficit has been found, however.

In Experiments 1 and 2, we examined children's inhibition by using variants of the retrieval practice paradigm. In this paradigm, it is demonstrated that the retrieval of a subset of learned material can cause forgetting of the nonretrieved material by inhibiting the interfering, notto-be-retrieved material (M. C. Anderson et al., 1994; M. C. Anderson \& Spellman, 1995). The results from the present experiments indicate that first and second graders already show inhibition of interfering material in this type of task. Moreover, the underlying inhibitory mechanism appears intact from first grade on.

In Experiment 2, we examined children's inhibition by using the part-list cuing paradigm. In this paradigm, it is demonstrated that cuing with a subset of studied material can have detrimental effects on recall of the remaining items. It has recently been suggested that part-list cuing induces covert retrieval of the cue items at test and, thus, causes inhibition of noncue items, which is very similar to the way overt retrieval causes forgetting of nonretrieved items (M. C. Anderson et al., 1994; Bäuml \& Aslan, 2004; Bäuml \& Kuhbandner, 2003). The results in Experiment 2 indicate that first graders already show detrimental effects of part-list cuing and that the size of the effect is about the same as that for older children and adults. This pattern suggests that, also in this type of episodic memory task, young children's inhibition is intact.

The difference in children's recall performance between directed forgetting, on the one hand, and retrievalinduced forgetting and part-list cuing, on the other, parallels results found with the elderly. Zacks et al. (1996) reported evidence that older adults show impaired directed forgetting, whereas Moulin et al. (2002) found robust retrieval-induced forgetting and Marsh, Dolan, Balota, and Roediger (2004) found robust part-list cuing in the elderly. Together with the present results on children's episodic recall, these findings on older adults' episodic recall indicate that retrieval-induced forgetting and part-list cuing develop early in life and remain intact for the greater part of the lifespan. Directed forgetting, instead, seems to develop relatively late and become impaired relatively soon.

It appears tempting to argue that the difference in the developmental course between retrieval-induced forgetting and part-list cuing, on the one hand, and directed forgetting, on the other, is related to frontal lobe functioning. There is evidence that the frontal lobes develop relatively late in childhood and, in late adulthood, show age-related decrements much earlier than the temporal lobes or the parietal and occipital lobes do (e.g., Madden \& Hoffman, 1997). It has been argued that the frontal lobes play an important role in directed forgetting (N. D. Anderson \& Craik, 2000), and the deficits found in both young children and older adults are, in fact, consistent with this view.

Because such deficits do not arise in retrieval-induced forgetting and part-list cuing, the frontal lobes should not play a major role in these types of inhibition. Corresponding evidence exists for part-list cuing. Although amnesic patients have been found to show larger detrimental effects of part-list cuing than healthy controls have, amnesic patients with frontal lesions showed the same detrimental effect as amnesic patients without frontal lesions (Bäuml et al., 2002). Also, schizophrenic patients with executive dysfunctions have been reported to show the same detrimental effect of part-list cuing as healthy controls (Kissler \& Bäuml, in press). These findings suggest that part-list cuing and, possibly, also retrieval-induced forgetting (but see Levy \& M. C. Anderson, 2002) depend to a lesser degree on the frontal lobes and to a larger degree on the temporal lobes. The issue requires further investigation, however - preferably, by using functional neuroimaging techniques.

Adults typically show much better recall performance than young children do in episodic memory tasks. To keep experimental conditions similar for adults and children, yet possible for children, recall performance thus is often close to ceiling for adults. This was also the case 
in the present experiments. There is evidence that such ceiling effects did not bias our conclusions, however. First, the amount of forgetting found in the data for the children was slightly larger than that found in the data for the adults (see Figures 1 and 2), thus leaving room for a possible underestimation of adult inhibition. Second, when splitting our adult group, we found the same amount of forgetting in adults with higher recall levels as in adults with lower recall levels; this is consistent with the literature showing that, if anything, higher recall levels are subject to more inhibition than lower recall levels are (M. C. Anderson et al., 1994; Bäuml, 1998; Bäuml \& Kuhbandner, 2003). Because there is also evidence that amount of inhibition is independent from the recall level of the to-be-practiced items (M. C. Anderson et al., 1994), it is, all in all, likely that we came up with a reasonable estimate of the true size of adult inhibition.

As in previous studies of retrieval-induced forgetting in the elderly (Moulin et al., 2002), in the present study, retrieval-induced forgetting in children was examined, using a free recall test. A priori, retrieval-induced forgetting as found in free recall need not necessarily be due to inhibition. Because in free recall practiced items are typically recalled before unpracticed ones, the practiced items may block recall of the unpracticed items and, thus, cause forgetting without inhibition (e.g., Rundus, 1973). Such a blocking account of retrieval-induced forgetting has been rejected for young adults, because the forgetting has been shown not only to occur in free recall, but to occur in cued recall with explicit control of output order and tests using the independent cue technique as well (see M. C. Anderson, 2003). To strengthen the conclusion that children and older adults show intact retrieval inhibition, future work needs to demonstrate that the retrievalinduced forgetting found in children's and older adults' free recall generalizes to other memory tasks.

In the present study, we assumed that part-list cuing, like retrieval-induced forgetting, is caused by retrieval inhibition. The present finding of parallel effects of retrieval practice and part-list cuing is consistent with this proposal, as are the results of several previous studies in which the effects of retrieval practice and part-list cuing were compared directly (Bäuml \& Aslan, 2004; Bäuml $\&$ Kuhbandner, 2003). There are also noninhibitory accounts of part-list cuing in the literature, however. One such leading account is strategy disruption. According to strategy disruption, part-list cuing causes forgetting by disrupting subjects' preferred recall order (Basden \& Basden, 1995). In this sense, the present results may suggest that children show retrieval-induced forgetting as a result of inhibition and show part-list cuing as a result of strategy disruption. The present data cannot distinguish between strategy disruption and inhibition. At this point in time, however, we favor the inhibitory account, because it provides the more parsimonious explanation of the results. Whether this preference is justified will be shown in future work.

\section{REFERENCES}

ACKERMAN, B. (1996). Induction of a memory retrieval strategy by young children. Journal of Experimental Child Psychology, 62, 243-271.

Anderson, M. C. (2003). Rethinking interference theory: Executive control and the mechanisms of forgetting. Journal of Language \& Memory, 49, 415-445.

ANDERSON, M. C., BJORK, R. A., \& BJORK, E. L. (1994). Remembering can cause forgetting: Retrieval dynamics in long-term memory. Journal of Experimental Psychology: Learning, Memory, \& Cognition, 20, 1063-1087.

Anderson, M. C., \& Spellman, B. (1995). On the status of inhibitory mechanisms in cognition: Memory retrieval as a model case. Psychological Review, 102, 68-100.

Anderson, N. D., \& CraiK, F. I. M. (2000). Memory in the aging brain. In E. Tulving \& F. I. M. Craik (Eds.), The Oxford handbook of memory (pp. 411-426). Oxford: Oxford University Press.

BASDEN, D. R., \& BASDEN, B. H. (1995). Some tests of the strategy disruption hypothesis of part-list cuing inhibition. Journal of Experimental Psychology: Learning, Memory, \& Cognition, 21, 1656-1669.

BäUML, K.-H. (1998). Strong items get suppressed, weak items do not: The role of item strength in output interference. Psychonomic Bulletin \& Review, 5, 459-463.

BäUML, K.-H. (2002). Semantic generation can cause episodic forgetting. Psychological Science, 13, 357-361.

BäUML, K.-H., \& Aslan, A. (2004). Part-list cuing as instructed retrieval inhibition. Memory \& Cognition, 32, 610-617.

BäUML, K.-H., \& HARTINGER, A. (2002). On the role of item similarity in retrieval-induced forgetting. Memory, 10, 215-224.

BÄUML, K.-H., KISSLER, J., \& RAK, A. (2002). Part-list cuing in amnesic patients: Evidence for a retrieval deficit. Memory \& Cognition, 30, 862-870.

BäUmL, K.-H., \& Kuhbandner, C. (2003). Retrieval-induced forgetting and part-list cuing in associatively structured lists. Memory \& Cognition, 31, 1188-1197.

BJork, E. L., BJork, R. A., \& ANderson, M. C. (1998). Varieties of goal-directed forgetting. In J. M. Golding \& C. M. MacLeod (Eds.), Intentional forgetting: Interdisciplinary approaches (pp. 103-137). Mahwah, NJ: Erlbaum.

BJORK, R. A. (1970). Positive forgetting: The noninterference of items intentionally forgotten. Journal of Verbal Learning \& Verbal Behavior, 9, 255-268.

BJork, R. A. (1989). Retrieval inhibition as an adaptive mechanism in human memory. In H. L. Roediger III \& F. I. M. Craik (Eds.), Varieties of memory and consciousness (pp. 309-330). Hillsdale, NJ: Erlbaum.

BJoRKLUND, D. F., \& HARNishfEGER, K. K. (1990). The resources construct in cognitive development: Diverse sources of evidence and a theory of inefficient inhibition. Developmental Review, 10, 48-71.

BJoRKLUnd, D. F., \& Zeman, B. R. (1982). Children's organization and metamemory awareness in their recall of familiar information. Child Development, 53, 799-810.

Bray, N. W., Justice, E. M., \& Zahm, D. N. (1983). Two developmental transitions in selective remembering strategies. Journal of Experimental Child Psychology, 36, 43-55.

Ciranni, M. A., \& Shimamura, A. P. (1999). Retrieval-induced forgetting in episodic memory. Journal of Experimental Psychology: Learning, Memory, \& Cognition, 25, 1403-1414.

Conway, M. A., Harries, K., Noyes, J., Racsma'ny, M., \& Frankish, C. R. (2000). The disruption and dissolution of directed forgetting: Inhibitory control of memory. Journal of Memory \& Language, 43, 409-430.

Diamond, A. (1988). Abilities and neural mechanisms underlying AB performance. Child Development, 59, 523-527.

HABERLANDT, K. (1999). Human memory: Exploration and application. Boston: Allyn \& Bacon.

HARNishfeger, K. K., \& BJorkLUND, D. F. (1993). The ontogeny of inhibition mechanisms: A renewed approach to cognitive development. In M. L. Howe \& R. Pasnak (Eds.), Emerging themes in cognitive development (pp. 28-49). New York: Springer-Verlag. 
Harnishfeger, K. K., \& Pope, R. S. (1996). Intending to forget: The development of cognitive inhibition in directed forgetting. Journal of Experimental Child Psychology, 62, 292-315.

Hasselhorn, M., \& Grube, D. (1994). Erstassoziationen zu 53 konkreten Substantiven. In W. Hager \& M. Hasselhorn (Eds.), Handbuch deutschsprachiger Wortnormen (pp. 59-64). Göttingen: Hogrefe.

KISSLER, J., \& BäUML, K.-H. (in press). Memory retrieval in schizophrenia: Evidence from part-list cuing. Journal of the International Neuropsychological Society.

Kobasigawa, A. (1974). Utilization of retrieval cues by children in recall. Child Development, 45, 127-134.

LeVy, B. J., \& ANDERSON, M. C. (2002). Inhibitory processes and the control of memory retrieval. Trends in Cognitive Sciences, 6, 299305.

LURIA, A. R. (1961). The role of speech in the regulation of normal and abnormal behavior. New York: Pergamon.

MacLeod, C. M. (1998). Directed forgetting. In J. M. Golding \& C. M. MacLeod (Eds.), Intentional forgetting: Interdisciplinary approaches (pp. 1-57). Mahwah, NJ: Erlbaum.

MacLeod, C. M., Dodd, M. D., Sheard, E. D., Wilson, D. E., \& BIBI, U. (2003). In opposition to inhibition. In B. H. Ross (Ed.), The psychology of learning and motivation (Vol. 43, pp. 163-214). San Diego: Academic Press.

Macrae, C. N., Bodenhausen, G. V., Milne, A. B., \& Ford, R. L. (1997). On the regulation of recollection: The intentional forgetting of stereotypical memories. Journal of Personality \& Social Psychology, 72, 709-719.

MADDEN, D. J., \& HofFMAN, J. M. (1997). Application of positron emission tomography to age-related cognitive changes. In K. R. R. Krishnan \& P. M. Doraiswamy (Eds.), Brain imaging in clinical psychiatry (pp. 575-613). New York: Dekker.

Marsh, E. J., Dolan, P. O., Balota, D. A., \& Roediger, H. L., III (2004). Part-set cuing effects in younger and older adults. Psychology \& Aging, 19, 134-144.

Moulin, C. J. A., Perfect, T. J., Conway, M. A., North, A. S., Jones, R. W., \& JAMES, N. (2002). Retrieval-induced forgetting in Alzheimer's disease. Neuropsychologia, 40, 862-867.

Nickerson, R. S. (1984). Retrieval inhibition from part-set cuing: A persisting enigma in memory research. Memory \& Cognition, 12, 531-552.

Roediger, H. L., III, \& MCDermott, K. B. (1995). Creating false memories: Remembering words not presented in lists. Journal of Experimental Psychology: Learning, Memory, \& Cognition, 21, 803-814.

Roediger, H. L., III, \& NeELY, J. H. (1982). Retrieval blocks in episodic and semantic memory. Canadian Journal of Psychology, 36, 213-242.

RoEdiger, H. L., III, \& SCHMIDT, S. R. (1980). Output interference in the recall of categorized and paired associate lists. Journal of Experimental Psychology: Human Learning \& Memory, 6, 91-105.

Roediger, H. L., III, Stellon, C. C., \& Tulving, E. (1977). Inhibition from part-list cues and rate of recall. Journal of Experimental Psychology: Human Learning \& Memory, 3, 174-188.
Rundus, D. (1973). Negative effects of using list items as recall cues. Journal of Verbal Learning \& Verbal Behavior, 12, 43-50.

SahaKyan, L., \& Kelley, C. M. (2002). A contextual change account of the directed forgetting effect. Journal of Experimental Psychology: Learning, Memory, \& Cognition, 28, 1064-1072.

Simpson, G. B., \& FosteR, M. R. (1986). Lexical ambiguity and children's word recognition. Developmental Psychology, 22, 147-154.

Slamecka, N. J. (1968). An examination of trace storage in free recall. Journal of Experimental Psychology, 76, 504-513.

Smith, A. D. (1971). Output interference and organized recall from long-term memory. Journal of Verbal Learning \& Verbal Behavior, 10, 400-408.

Strutt, G. F., Anderson, D. R., \& Well, A. D. (1975). A developmental study of the effects of irrelevant information on speeded classification. Journal of Experimental Child Psychology, 20, 127-135.

TipPer, S. P., Bourque, T. A., ANderson, S. H., \& Brehaut, J. (1989). Mechanisms of attention: A developmental study. Journal of Experimental Child Psychology, 48, 353-378.

WILsON, S. P., \& KIPP, K. (1998). The development of efficient inhibition: Evidence from directed-forgetting tasks. Developmental Review, 18, 86-123.

Zacks, R. T., Radvansky, G. A., \& Hasher, L. (1996). Studies of directed forgetting in older adults. Journal of Experimental Psychology: Learning, Memory, \& Cognition, 22, 143-156.

\section{NOTES}

1. There is another method of studying directed forgetting, the socalled item method (see MacLeod, 1998). In this method, each item individually is followed by a forget or a remember cue, with the two kinds of items randomly intermingled during list presentation. With the item method, young children typically show poor directed forgetting (Wilson \& Kipp, 1998). The deficit, however, is commonly attributed to differential encoding, rather than to inhibition.

2. English translations of the (originally German) item lists are available on request via e-mail.

3. The modified variant of the retrieval practice paradigm actually mimics the well-known output interference paradigm. The output interference effect describes the decline in an item's recall probability as a function of its serial position in a testing sequence (Roediger \& Schmidt, 1980; Smith, 1971). Both retrieval-induced forgetting and output interference have been suggested to be caused by retrieval inhibition (M. C. Anderson, 2003; Bäuml \& Hartinger, 2002).

4. An analogous subject split for the data in Experiment 1 revealed the same pattern of results. Good rememberers and poor rememberers did not vary in their amount of retrieval-induced forgetting $[F(1,22)<1]$.

(Manuscript received February 16, 2004; revision accepted for publication July 21,2004 .) 